\title{
IMMUNO-HISTOCHEMICAL CHANGES TRIGGERED BY REPEATED CRYPTOSPORIDIUM INFECTION IN IMMUNOSUPPRESSED MICE
}

\author{
By
}

MENNAT EL-RAHMAN A. FAHMY ${ }^{1}$, HEBAT-ALLAH SALAH A. YOUSOF ${ }^{2 *}$, SHAIMAA H. EL-SAYED ${ }^{3}$, SOHEIR S. MAHMOUD ${ }^{1}$, MONA MAGDY, MAISA A. SHALABY ${ }^{1}$ AND MOUSA A. M. ISMAIL ${ }^{2}$

Department of Medical Parasitology ${ }^{1}$, Theodor Bilharz Research Institute, Imbaba,

P.O. Box 30 Giza, Department of Medical Parasitology ${ }^{2}$, Kasr Al-Ainy Faculty of Medicine, Cairo University, P.O. Box 11562 Cairo, Department of Medical

Parasitology ${ }^{3}$, Faculty of Medicine, Helwan University, and Department of Pathology 4 ,

Theodor Bilharz Research Institute, Imbaba, P. O. Box 30 Giza, Egypt.

( ${ }^{*}$ Correspondence: drhebasalah@kasralainy.edu.eg, drhebasalah@hotmail.com)

\section{Abstract}

Cancers are increasing at an alarming rate with a potential association between parasitosis and cancer. This study was conducted on 190 albino mice to evaluate the possible histopathological changes and immunohistochemical alteration in the expression of $\beta$-catenin and p53 as markers of cellular proliferation in ileocecal region induced by chronic irritation with Cryptosporidium oocysts. 180 experimentally immunosuppressed mice were divided into five groups, control noninfected, infected with 50 oocysts/mouse once, infected with 500 oocysts/mouse once, repeatedly infected with 50 oocysts/mouse/week and repeatedly infected with 500 oocysts/mouse/week. Each group was further subdivided into 3 subgroups according to the date designed for scarification. 10 naïve mice were used as negative control. Histopathological examination of the ileocecal region showed mild to severe villous atrophy and inflammatory exudation in colonic mucosa. Mice received high inoculum dose showed significantly severe histopathological changes. A progressive increase of cytoplasmic labeling of $\beta$-catenin without loss of $\beta$-catenin membrane labeling was recorded in groups infected once, in repeatedly infected ones; there was loss of $\beta$ catenin membrane labeling and progressive increase of the cytoplasmic labeling of $\beta$-catenin without nuclear expression of $\beta$-catenin or nuclear expression of $\mathrm{p} 53$ in all infected groups.

Key Words: Cryptosporidium, histopathological, immuno-histochemical, $\beta$-catenin, immunosuppressed mice.

\section{Introduction}

Cryptosporidiosis is one of the world's most common causes of diarrheal disease in humans, especially children, aged and AIDS patients (Xiao, 2010). It is caused by the Apicomplexan protozoa of the genus Cryptosporidium, which are unicellular organisms possessing an apical complex believed to be involved in the host cell invasion (Cama et al, 2007). Many species, genotypes and subtypes of the genus Cryptosporidium can infect a varied range of vertebrates including humans. C. hominis and C. parvum are the most commonly detected species in human infections. Both species have diverse host ranges; $C$. hominis is restricted mostly to humans, whereas $C$. parvum infects humans and ruminants (Molloy et al, 2010). The principal site of infection with $C$. homi- nis and C. parvum is the small intestine. In some animals such as mice and calves, the ileum above the cecal junction is the preferential location for $C$. parvum. It was also found in extra-intestinal sites of infected animals (Fleta et al, 1995) and in some severely the immunocompromised humans (Hunter and Nichols, 2002). Assumed virulence factors of Cryptosporidium including excystation, gliding motility, attachment, invasion, parasitophorous vacuole development, intracellular maintenance and host cell destruction have been involved in the early interaction processes of Cryptosporidium oocysts and sporozoites with the host epithelial cells (Wanyiri and Ward, 2006).

Infection might be one of the important the causes of cancer. In 2002, the estimated total cancer attributable to infections was $17.8 \%$ 
of the overall cancer burden. The main documented agents were the bacterium Helicobacter pylori, the human papilloma viruses, the hepatitis B and $C$ viruses, Epstein-Barr virus (EBV), human immunodeficiency virus (HIV) together with the human herpes virus 8 and Human $T$ cell lymphotropic virus type I (HTLV-I) (Parkin, 2006).

Other pathogens including parasites can similarly cause cancer. For example, the digenetic trematode Schistosoma haematobium can cause urinary bladder cancer and the liver flukes Opisthorchis viverrini and Clonorchis sinensis were causally associated with cholangiocarcinoma. Besides, the link of some Apicomplexan and Flagellate species with neoplastic changes in the host tissues was suspected (De Martel and Franceschi, 2009).Excitingly, inhibition of apoptosis was described in Apicomplexan protozoa (Carmen \& Sinai, 2007). Apoptosis prevention possibly benefits the parasite by stabilizing the host cell long enough to permit the accomplishment of the life cycle. Resistance to apoptosis could be a crucial step in the development to malignancy (Lowe and Lin, 2000; Heussler et al, 2001). There were some assumptions about the possible links between cryptosporidiosis and neoplasia in humans. Different evidence has shown direct or indirect association between cryptosporidiosis and cancer in different human residents. Among HIV-infected persons the colorectal cancer incidence was greater than in the general population (Patel et al, 2008).

Infection played an essential role in the cancer etiology. So, there will be fewer cancer cases if infections associated with cancers were prevented. Research on that area could be valuable since the incidence of Cryptosporidium infection seems to increase not only among immunosuppressed patients but correspondingly in the general population worldwide.

\section{Materials and Methods}

Experimental animals: The study was carried out on 190 clean laboratory bred male Swiss Albino mice 7 weeks old provided by
Schistosoma Biological Supply Program (SBSP) in Theodor Bilharz Research Institute (TBRI). Animals were kept on a standard regimen containing $24 \%$ protein, $4 \%$ fat, about $4-5 \%$ fiber and water ad-libitumin under a temperature of $24^{\circ} \mathrm{C}$. Animals were screened to exclude parasitic infections. Experiment was carried out according to The Clinical and Laboratory Standards Institute (CLSI) guidelines and was approved by ethical committee of TBRI and Kasr-Al-Ainy Faculty of Medicine.Immunosuppression of experimental animals: One hundred eighty mice received synthtic corticosteroids (dexamethasone) orally by eosophageal tube at a dose of $0.25 \mu \mathrm{g} / \mathrm{g} /$ day dissolved in $200 \mu \mathrm{l}$ of distilled water/ mouse for 14 successive days preceding inoculation with Cryptosporidium oocysts and continued receiving dexamethasone at the same dose throughout the experiment (Rehg et al, 1988).

Animal grouping: One hundred ninety mice were included in this experiment. Mice were divided into 180 experimentally immunosuppressed mice and 10 naïve (non-immunosuppressed, non-infected) mice served as negative control group. Immunosuppressed mice were divided into five groups: G1: consisted of 20 non-infected immunosuppressed mice served as control. G2: contained 30 immunosuppressed mice infected once with 50Cryptosporidium spp. oocysts/ mouse. G3: consisted of 30 immunosuppressed mice once infected with 500 Cryptosporidium spp. oocysts/mouse. G4: consisted of 50 immunosuppressed mice infected with 50 Cryptosporidium oocysts/mouse/ week. G5: consisted of 50 immunosuppressed infected mice with 500 Cryptosporidium spp. oocysts /mouse/ week. Each group of immunosuppressed mice was subdivided into 3 subgroups; A, B \& C according to date designed for scarification $\left(25,35 \& 46\right.$ days post $1^{\text {st }}$ infection of infected groups respectively).

Oocysts were isolated from diarrheic calves by Lumb's technique (Lumb et al, 1993). Oocysts were mixed with an equal volume of $2.5 \%$ potassium dichromate $(\mathrm{K} 2 \mathrm{Cr} 2 \mathrm{O} 7)$ 
and stored at $4^{\circ} \mathrm{C}$ until use for inoculation (Current et al, 1983, khalifa et al, 2001). Just before use, Cryptosporidium oocysts were washed for at least three times with distilled water to get rid of the potassium dichromate and centrifuged at $1500 \mathrm{xg}$ for 15 min. each until cleared (Gaafar, 2007). 3 slides; each was formed of $50 \mu$ l were prepared from sample and stained with modified Zeihl-Neelsen (MZN) and compared with control positive stained slides. Oocysts were counted in each slide, and the mean number of the counted oocysts was calculated to get the number of oocysts in $1 \mathrm{ml}$ of sample (Garcia and Bruckner, 1997).

Mice from G2, G3, G4 \& G5 were infected with the designed number of Cryptosporidium spp oocysts orally using the eosophageal tube (care should be taken to avoid traumatic injury of mice throat). Mice were kept in clean cages and fecal pellets were collected from inoculated mice individually stating from the $3^{\text {rd }}$ day post infection and subjected to parasitological examination using the MZN stain (cold method) to detect C. parvum oocysts and to confirm infection (Garcia, 2007).Mice from G4 \& G5 were repeatedly infected weekly throughout the study by intragastric inoculation of 50 Cryptosporidium spp. oocysts/mouse/week (G4), and 500 oocysts/mouse/week (G5). All mice were transferred to new cage every other day throug-out the experiment. Mice scarification was done by giving anesthetic-anticoagulant solution $(500 \mathrm{mg} / \mathrm{kg}$ thiopental \& 100units/ml heparin) by intraperitoneal injection (Liang et al, 1987). This was done as follows: Gs 1a, 2a, 3a, 4a \& 5a were sacrificed at $25^{\text {th }}$ day post $1^{\text {st }}$ infection. Gs $1 b, 2 b$, $3 \mathrm{~b}, 4 \mathrm{~b} \& 5 \mathrm{~b}$ : were sacrificed at $35^{\text {th }}$ day post $1^{\text {st }}$ infection. Gs 1c, 2c, 3c, 4c \& 5c: were sacrificed at $46^{\text {th }}$ day post $1^{\text {st }}$ infection. Ileocecal regions were removed for histopathological and immunohistochemical examination.

Parasitological evaluation: Fresh fecal pellets from each group were collected from the third day post first infection and every 3 days until the end of the experiment. Samples were subjected to parasitological examination using modified Ritchie's concentration method, stained with MZN (cold method) and examined by oil immersion to count oocysts in 50 $\mu 1$ (Garcia, 2007). Number was expressed per gram of feces (Benamrouz et $a l$, 2012). Excised ileo-caecal regions for histopathological processing at Department of Pathology, TBRI after Drury and Wallington (1980). Sections of $4 \mu \mathrm{m}$ thickness were stained with Haematoxylin \& Eosin $(\mathrm{H}$ $\&$ E) to detect changes in the ileo-caecal region due to repeated infection and inflammation grading due to cellular infiltr- ation heaviness, lymphocytic aggregation and degree of villous \& crypt damage; mild, moderate or severe (Dieleman et al, 1998).

Immuno-histochemical evaluation of repeated infection (Godbole et al, 2007): 1- Preparation of paraffin sections: Paraffin blocks were sectioned at $5 \mu \mathrm{m}$ thickness by a microtome and floated on a $40^{\circ} \mathrm{C}$ water bath with distilled water, transported onto adhesive microscope slides, and allowed to dry overnight at room temperature. Adhesion of section to slide was crucial to prevent tissue loss during consequent incubations and washes. 2- De-paraffinization and rehydration of tissue slides: Slides were placed in a $55^{\circ} \mathrm{C}$ oven for ten minutes to melt paraffin, de-paraffinized in two changes of xylene or xylene substitute for 5 minutes each, transferred to absolute ethanol, two changes for 3 minutes each, and transferring once through 95\% ethanol for 3 minutes. Endogenous biotin activity was blocked by incubating sections in $3 \% \mathrm{H}_{2} \mathrm{O}_{2}$ solution in methanol for 10 minutes, and slides were rinsed in PBS twice for 5 minutes each time. Antigen retrieval was performed in all cases by slides steam heating in a 1-mmol/L EDTA solution ( $\mathrm{pH}$ 8.0) for 30 minutes. Immuno-histochemical staining of paraffin-embedded tissues by using p53 \& $\beta$-catenin antibodies at 1:50 dilution (DAKO): Staining by an automated immunostainer (DAKO) followed by detection by using the streptavidin-biotin detection 
system (DAKO).

Immuno-histochemical examinations: All slides were manually scored since the expression of $\beta$-catenin and p53 were found to be heterogeneous and variances in the intensity of staining of membrane and cytoplasm. Three random sections from each group was scored for staining intensity (0: no staining, 1: mild cytoplasmic, 2: moderate cytoplasmic, 3: weak nuclear and cytoplasmic, 4: strong cytoplasmic).Data for statistical analysis was tabulated, and analyzed according to each parameter type. $\mathrm{M} \pm \mathrm{SD}$ was done for parametric numerical data. ANOVA test assessed the significance between all groups followed by Post Hoc tests to compare significance between all groups. P-value was significant at $<0.05$. The histopathological and Immunohistochemical data were analyzed using one of the non-parametric tests $(\mathrm{Kr}-$
uskal-Wallis test) and data were expressed in median.

\section{Results}

Mice started to show signs of immunossuppression after one week of drug administration in the form of hair loss, ulceration, abscess formation and subcutaneous edema.

Parasitological evaluation of infection (oocyst shedding monitoring): by susceptibility of mice when challenged with different intended doses and influence of Cryptosporidium's inoculum size on the intensity of oocyst shedding, amount of oocyst in one gram stool was estimated periodically. Oocyst shedding started at $6^{\text {th }}$ day PI in G2 \& G3 (mice inoculated with low dose of oocysts) and at the $3^{\text {rd }}$ day PI in G4 \& G5 (mice inoculated with high dose of oocysts).All groups showed a high level of oocyst excretion up to last experimental day (Tab. 1).

Table 1: Comparison between mean numbers of oocysts/gm feces $\times 10^{3}$ shed at different days post-infection in groups.

\begin{tabular}{|c|c|c|c|c|}
\hline Group & Time of stool examination & Infection Frequency & Infection Dose (oocysts/mouse) & $(\mathrm{M} \pm \mathrm{SD}) \times 10^{3}$ \\
\hline G2a & \multirow{4}{*}{ Day 25 PI } & \multirow{2}{*}{ Single } & 50 & $8.05 \pm 0.9 *$ \\
\hline G3a & & & 500 & $60.01 \pm 10.2^{*}$ \\
\hline G4a & & \multirow{2}{*}{ Repeated } & 50 & $13.18 \pm 3.05^{*}$ \\
\hline G5a & & & 500 & $121.3 \pm 15.7 *$ \\
\hline $\mathrm{G} 2 \mathrm{~b}$ & \multirow{4}{*}{ Day 35 PI } & \multirow{2}{*}{ Single } & 50 & $9 \pm 1.1 * *$ \\
\hline G3b & & & 500 & $71.6 \pm 7.9 * *$ \\
\hline G4b & & \multirow{2}{*}{ Repeated } & 50 & $40.5 \pm 16.3^{* *}$ \\
\hline G5b & & & 500 & $160.7 \pm 29.2 * *$ \\
\hline $\mathrm{G} 2 \mathrm{c}$ & \multirow{4}{*}{ Day 46 PI } & \multirow{2}{*}{ Single } & 50 & $10.04 \pm 1.75$ \\
\hline G3c & & & 500 & $80.4 \pm 14.03^{* * *}$ \\
\hline G4c & & \multirow{2}{*}{ Repeated } & 50 & $80.8 \pm 13.3 * * *$ \\
\hline G5c & & & 500 & $200.7 \pm 28.9$ \\
\hline
\end{tabular}

*Significant difference $(<0.01)$ with other Gs (a), ** Significant difference $(<0.01)$ with other Gs $(\mathrm{b})$, *** Significant difference $(<0.01)$ with Gs $2 c \& 5 c$.

Histopathological appearance of Cryptosporidium oocyts: In $\mathrm{H} \& \mathrm{E}$ stained sections of infected mice, oocyts appeared as tiny round basophilic organisms measured 4$6 \mu \mathrm{m}$ in diameter seen along the enterocyte microvillous borders especially near the villous tip. Also, several degrees of inflammatory changes seen in the ileal regions by all the infected groups that ranged from mild to severe active ileitis in form of decreased villous height ratio to crypt length, loss of villous architecture, shortening and broadening of villi, loss of brush border micro-villous surface area, edema of lamina propria with mixed inflammatory cellular infiltrate in- cluding plasma cells and lymphocytes with depletion of goblet cells (Fig. 1), with significant difference between groups as regards ileitis severity (Tab. 2). Also, in colon: several degrees of inflammatory changes were seen in all groups infected with the parasites ranging from focal mild colitis to moderate colitis with moderate exudation of mononuclear inflammatory cells including plasma cells, lymphocytes and histeocytes with pleomorphic hyperchromatic nuclei (Fig. 1), without significant difference of colitis severity between all groups (Tab. 2).

Immunohistochemical detection of $\beta$-catenin cellular localization in iliocecal region as 
was detected by brown staining in membrane and/or cytoplasm of enterocytes, and in inflammatory cells of lamina propria (intensity staining). But, in mucosa of ileocaecal regions of the non-infected control mice, $\beta$-catenin labeling was moderate and exclusively localized to cell membrane (Tab. 3; Fig. 2). Plenty of oocysts were detected in the colon of groups repeatedly infected with high dose of oocysts (500 oocysts) and scarified at the $25^{\text {th }}, 35^{\text {th }}$, and $46^{\text {th }}$ days post first infection expressing $\beta$-catenin staining (Fig. 2).

Immunohistochemical detection of p53 cellular localization in ilio-caecal region in infected mice, when only repeatedly infected with high dose of oocysts (500 oocysts) and sacrificed at $25^{\text {th }}, 35^{\text {th }}$, and $46^{\text {th }}$ days post first infection showed focal mild cytosolic p53 labeling in lamina propria (Fig. 2) when compared to non-infected mice which did not detect p53.

Table 2: Histopathological scoring of severity of ileitis and colitis in infected groups.

\begin{tabular}{|c|c|c|c|c|c|c|c|}
\hline \multirow{2}{*}{$\begin{array}{l}\text { Animal } \\
\text { group }\end{array}$} & \multirow{2}{*}{$\begin{array}{c}\text { Time of } \\
\text { scarification }\end{array}$} & \multirow{2}{*}{$\begin{array}{c}\text { Infection } \\
\text { Type }\end{array}$} & \multirow{2}{*}{$\begin{array}{l}\text { Infection Dose } \\
\text { (oocysts/mouse) }\end{array}$} & \multicolumn{2}{|c|}{ severity of ileitis } & \multicolumn{2}{|c|}{ severity of colitis } \\
\hline & & & & $<2$ & $>2$ & 0 & $>0$ \\
\hline G2a & \multirow{4}{*}{ Day 25 PI } & \multirow{2}{*}{ Single } & 50 & $100 \% *$ & $0 \% *$ & $100 \%$ & $0 \%$ \\
\hline G3a & & & 500 & $80 \% *$ & $20 \% *$ & $40 \% \wedge$ & $60 \%{ }^{\wedge}$ \\
\hline G4a & & \multirow{2}{*}{ Repeated } & 50 & $90 \% *$ & $10 \% *$ & $90 \% *$ & $10 \% *$ \\
\hline G5a & & & 500 & $20 \%$ & $80 \%$ & $10 \% \wedge$ & $90 \% \wedge$ \\
\hline G2b & \multirow{4}{*}{ Day 35 PI } & \multirow{2}{*}{ Single } & 50 & $100 \%$ & $0 \%$ & $100 \%$ & $0 \%$ \\
\hline G3b & & & 500 & $60 \% * *$ & $40 \% * *$ & $30 \% * *$ & $70 \%$ ** \\
\hline G4b & & \multirow{2}{*}{ Repeated } & 50 & $73 \% * *$ & $27 \% * *$ & $53 \%$ & $47 \%$ \\
\hline G5b & & & 500 & $27 \% * *$ & $73 \% * *$ & $20 \% * *$ & $80 \%$ ** \\
\hline G2c & \multirow{4}{*}{ Day 46 PI } & \multirow{2}{*}{ Single } & 50 & $100 \%$ & $0 \%$ & $90 \%$ & $10 \%$ \\
\hline G3c & & & 500 & $40 \% * * *$ & $60 \% * * *$ & $20 \% * * *$ & $80 \%$ **** \\
\hline G4c & & \multirow{2}{*}{ Repeated } & 50 & $32 \% * * *$ & $68 \% * * *$ & $16 \% * * *$ & $84 \% * * *$ \\
\hline G5c & & & 500 & $16 \%$ *** & $84 * * *$ & $8 \% * * *$ & $92 \% * * *$ \\
\hline
\end{tabular}

${ }^{\wedge}$ Significant difference $(<0.01)$ with G2a, *Significant difference $(<0.01)$ with G5a, ** Significant difference $(<0.01)$ with $\mathrm{G} 2 \mathrm{~b}, * * *$ Significant difference $(<0.01)$ with G2c.

Table 3: Immunohistochemical staining intensity of $\beta$-catenin expression in infected groups

\begin{tabular}{|c|c|c|c|c|c|}
\hline \multirow{2}{*}{$\begin{array}{l}\text { Animal } \\
\text { group }\end{array}$} & \multirow{2}{*}{$\begin{array}{c}\text { Time of scarifica- } \\
\text { tion }\end{array}$} & \multirow{2}{*}{$\begin{array}{l}\text { Infection } \\
\text { Frequency }\end{array}$} & \multirow{2}{*}{$\begin{array}{l}\text { Infection Dose } \\
\text { (oocysts/mouse) }\end{array}$} & \multicolumn{2}{|c|}{ staining intensity of abnormal $\beta$-catenin } \\
\hline & & & & Score of 0 & $>0$ \\
\hline G2a & \multirow{4}{*}{ Day 25 PI } & \multirow{2}{*}{ Single } & 50 & $100 \%$ & $0 \%$ \\
\hline G3a & & & 500 & $80 \%{ }^{\wedge}$ & $20 \% \wedge$ \\
\hline G4a & & \multirow{2}{*}{ Repeated } & 50 & $0 \% *$ & $100 \% *$ \\
\hline G5a & & & 500 & $0 \% *$ & $100 \% *$ \\
\hline G2b & \multirow{4}{*}{ Day 35 PI } & \multirow{2}{*}{ Single } & 50 & $87 \%$ & $13 \%$ \\
\hline G3b & & & 500 & $67 \%$ & $33 \%$ \\
\hline G4b & & \multirow{2}{*}{ Repeated } & 50 & $0 \% * *$ & $100 \% * *$ \\
\hline G5b & & & 500 & $0 \% * *$ & $100 \% * *$ \\
\hline G2c & \multirow{4}{*}{ Day 46 PI } & \multirow{2}{*}{ Single } & 50 & $80 \%$ & $20 \%$ \\
\hline G3c & & & 500 & $0 \% * * *$ & $100 \% * * *$ \\
\hline G4c & & \multirow{2}{*}{ Repeated } & 50 & $0 \% * * *$ & $100 \% * * *$ \\
\hline G5c & & & 500 & $0 \% * * *$ & $100 \% * * *$ \\
\hline
\end{tabular}

^ Significant difference $(<0.01)$ with G2a, *Significant difference $(<0.01)$ with Gs 2a\& 3a., ** Significant difference $(<0.01)$ with Gs $2 b \& 3 b$, *** Significant difference $(<0.01)$ with G2c

\section{Discussion}

Persistent infection with Cryptosporidium could carry a risk for induction of gastrointestinal neoplastic alterations. Resistance to apoptosis was a crucial step in progression to malignancy (Lowe and Lin, 2000). Cryptosporidium is able to activate NF- $\mathrm{NB}$ pathway, inhibiting the induction of cell death early after infection. Apoptosis prevention possibly benefits the parasite by stabilizing the host cell long enough to permit the completion of life cycle (Heussler et al, 2001).

In the current work, dexamethasone was used to induce chemical immunosuppression in the mice. Glucocorticoids are well-known to have an effect on the priming of the innate immune response and could suppress IFN- $\gamma$ -regulated gene expression and improve de- 
fect in $\mathrm{T}$ and $\mathrm{B}$ lymphocytes making mice more vulnerable to the infection and to develop a chronic disease (Franchimont, 2004 and Stojadinovic et al, 2007). All infected groups showed a high level of oocysts excretion starting from the $6^{\text {th }}$ day P.I. after inoculation with 50 oocysts, and from the 3rd day P.I. in mice inoculated with 500 oocysts until the last day of the experiment. This might be due to failure in immune system to get rid of the parasite. This data agreed with Certad et al. (2007) who found that among C. parvum-infected mice; Dex-treated SCID mice became chronic shedders with an average prepatent period of 6.2 days.

Days of scarification were chosen to detect the immunohistochemical changes in dysplastic abnormally proliferating cells in the ileo-cecal region, even before histopathological evidence of neoplasia, as increased expression of $\beta$-catenin was considered as an early event in colorectal carcinogenesis and usually followed by a later mutational inactivation of p53 tumor suppressor (Cooper et $a l, 2000)$. Histopathological changes of ileocecal sections showed remarkable effect on the structure of the intestinal mucosa (mild, moderate \& severe active ileitis with mild to moderate colitis) compared to that of the non-infected control group.Studies revealed comparable findings with variable histopathological changes ranging from partial to complete villous atrophy and inflammatory infiltrate attributed to cryptosporidiosis (Abuel Ezz et al, 2011; Al-Mathal and Alsalem, 2012; Al-Warid et al, 2013; Taha et al, 2017). Also,unlike Certad et al. (2007) who observed mucosal changes suggestive of intraepithelial neoplasia in the ileocaecal region of a mouse euthanatized at day 46 postinfection, as no neoplastic changes in ileocecal region were detected. This might be attributed to the use of relatively higher infectious dose $\left(10^{5}\right.$ oocysts) in comparison with the relatively lower infectious doses used (50 \& 500 oocysts). Moreover, Certad et al. (2010) found that the SCID mice inoculated with higher inocula $\left(10^{6}-10^{7}\right)$ experienced more severe neoplastic growth and showed high grade intraepithelial neoplasia or adenomas with high grade dysplasia in the caecum after 46 days P.I. Conversely, Benamrouz et al. (2012) reported that $C$. parvum infection induced neoplastic lesions in the ileocecal region, which could change into an invasive adenocarcinoma following experimental infection with low doses,even with only one oocyst. This could be related to the degree of immunosuppression used which was found to be directly proportional to the risk of neoplastic change.

The infecting Cryptosporidium strain used seemed to have a major role in inducing neoplastic changes in the experimental mice model. Certad et al. (2010) used a diverse strain of Cryptosporidium and found that $C$. parvum TUM1 strain induced a more severe illness than $C$. parvum IOWA, with an earlier onset of neoplastic lesions that rapidly progressed to invasive cancer on day 20 P.I. Also, Certad et al. (2012) used C. parvum isolated from a patient's stool and was identified as $C$. parvum II2A15G2R1 (subtype linked to zoonotic exposure). This strain was inoculated into immunodeficient mice and induced not only severe infection, but also invasive gastrointestinal and biliary adenocarcinoma.

Since reactive atypical changes secondary to inflammation and infection could morphologically affect the epithelium of the gastrointestinal tract and mimic true dysplastic changes, determining the real dysplastic process using specific markers is mandatory (Bartkova et al, 2001).

In the present study, used proteins commonly involved in the cell cycle, differentiation and/or cell migration, such as $\beta$-catenin, and $\mathrm{p} 53$. $\beta$-catenin is a $92-\mathrm{kDa}$ protein that, together with E-cadherin, plays a role in cell-cell adhesion and is involved in intracellular signaling (Sayon et al, 2016) and that's why the membranous staining of the normal cells.It was remarkable the well defined association between $\beta$-catenin deregulation and the emergence of different types of can- 
cer, although implication of $\beta$-catenin was involved in tumorigenic processes when first recognized in colorectal cancer.

In colorectal adenomas and carcinomas, translocation of $\beta$-catenin from the cell membrane to cytoplasm and/or nucleus was stated, and considered as an early event in development of colorectal neoplasia (Takahashi et al, 2000) and usually followed by an advanced mutational inactivation of the p53 tumor suppressor (Cooper et al, 2000). A cellular pool of $\beta$-catenin binding $\mathrm{E}$ cadherin at cell-cell junctions was crucial in maintaining epithelial cell polarity and tissue architecture. Alteration in $\beta$-catenin expression reflected the alteration in APC/WNT signaling pathway, without dysplasia or malignancy (Curtis et al, 2010). Activation of WNT pathway in non-neoplastic cells results in disruption of CK1-GSK3 $\beta$-Axin-APC- $\beta$ catenin complex, inhibition of GSK3 $\beta$ activity, and the stabilization of $\beta$-catenin against degradation in the cytoplasm by ubiquitinproteasome pathway. Accumulation of $\beta$ catenin in the cytoplasm caused nuclear translocation (Sayon et al, 2016).

In the present study, abnormal localization of $\beta$-catenin was found in all infected mice. There was a significant progressive increase in the cytoplasmic labeling of $\beta$-catenin as reported by cytoplasmic staining due to accumulated $\beta$-catenin in the cytoplasm as a result of activation of WNT signaling by Cryptosporidium infection. $\beta$-catenin membrane labeling was preserved in groups infected once while, in repeatedly infected groups, there was a significant loss of $\beta$ catenin membrane labeling without observed nuclear expression of $\beta$-catenin. These findings agreed with that of Benamrouz et al. (2014) who reported progressive increase in the cytoplasmic labeling of $\beta$-catenin after 25 days post-infection, without loss of $\beta$ catenin membrane labeling and absence of $\beta$-catenin in the nucleus of ileo-caecal region even after 90 days post-infection. Consistently, $\beta$-catenin was not found in the nucleus of transformed lymphocytes infected with
Epstein-Barr virus (Everly et al, 2004).

The down regulation of E-cadherin and $\beta$ catenin accumulation in the cytoplasm/ nucleus was proposed to stimulate malignant transformation and advancement by triggering cyclin D1 expression in breast cancer (Yang and Weinberg, 2008). The loss of membranous $\beta$-catenin and increased cytoplasmic expression was significantly concomitant with oral squamous cell carcinoma and linked with aggressive tumor behavior and poor prognosis (Kaur et al, 2013). In the metastatic process, reduction of cell-cell adhesion including E-cadherin $\beta$-catenin cell adhesion complex is a crucial step. Kudo et al. (2004) reported that invasion and metastasis of oral cancer cells necessitate down regulation of E-cadherin and/or degradation of membranous $\beta$-catenin.No nuclear expression or alteration in the expression of p53 in ileo-caecal region was reported in this study contrasting Benamrouz et al. (2014) who found accumulation of p53 in the cytoplasm of cells of infected mice without nuclear expression of p53 in the adenomatous ileo-caecal region. This could be interrelated to the duration of the study as mutational inactivation of the p53 tumor suppressor occurred after a while from the translocation of $\beta$-catenin from cell membrane to cytoplasm and/or nucleus (Cooper et al, 2000). Murine $C$. parvum infection showed a potential function in suppression of intestinal stem cells and host cell apoptosis after infection, which gave some additional insights into the influence of cryptosporidiosis on intestinal epithelial growth (Xin-Tian et al, 2016).

\section{Conclusion}

Based on the alterations in expression of $\beta$-catenin and the induction of ileo-caecal adenocarcinoma byCryptosporidium spp.that was able to modulate host cytoskeleton activities and several host-cell biological processes through alteration in APC/ WNT signaling pathway through low dose of oocysts to develop histopathological and immunohistochemical alterations suggested that other mammalian species including humans 
could be vulnerable to this process as Dextreated mice were in severely immunocompromised state. These individuals must be protected against parasites such as Cryptosporidium spp. which can be transmitted easily from the environment.

\section{References}

Abu El Ezz, NT, Khalil FA, Shaapan, RM, 2011: Therapeutic effect of onion (Allium cepa) and Cinnamon (Cinnamomum zeylanicum) oils on cryptosporidiosis in experimentally infected mice. Global Veterinaria 7, 2:179-83.

Al-Matha, EA, Alsalem, MA, 2012: Pomegranate (Punica granatum) peel is effective in a murine model of experimental Cryptosporidium parvum. Exp. Parasitol. 131:350-7.

Al-Warid, HS, AL-Saqur, IM, Mahmood, SH, 2013: Histopathological changes in mice infected with Cryptosporidium spp. Int. J. Pharm. Bio. Sci. 3, 3:220-7.

Bartkova, J, Thullberg, M, Slezak, P, Jaramillo, E, Rubio, C, et al, 2001: Aberrant expression of G1-phase cell cycle regulators in flat and exophytic adenomas of the human colon. Gastroenterology 2, 120:1680-8.

Benamrouz, S, Conseil, V, Chabé, M, Praet, M, Audebert, C, et al, 2014: Cryptosporidium parvum-induced ileo-caecal adenocarcinoma and Wnt signaling in a mouse model. Dis. Model Mech. 7, 6:693-700.

Benamrouz, S, Guyot, K, Gazzola, S, Mouray, A, Chassat, T, et al, 2012: Cryptos-poridium parvum infection in SCID Mice Infected with only one oocyst: qPCR Assessment of Parasite Replication in Tissues and Development of Digestive Cancer. PLoS One 7, 12:512-32.

Cama, VA, Ross, JM, Crawford, S, Kawai, V, Chavez-Valdez, R, et al, 2007: Differences in clini-cal manifestations among Cryptosporidium species and subtypes in HIV-infected persons. J. Infect. Dis. 196:684-91.

Carmen, JC, Sinai, AP, 2007: Suicide prevention: Disruption of apoptotic pathways by protozo an parasites. Mol. Microbiol. 64:904-16.

Certad, G, Benamrouz, S, Guyot, K, Mouray, A, Chassat, T, et al, 2012: Fulminant cryptosporidiosis after near-drowning: A human Cryptosporidium parvum strain implicated in invasive gastrointestinal adenocarcinoma and cholangiocarcinoma in an experimental model. Appl. Environ. Microbial. 78:1746-51.

Certad, G, Creusy, C, Guyot, K, Mouray, A,
Chassat, T, et al, 2010: Fulminant cryptosporidiosis associated with digestive adenocarcinoma in SCID mice infected with Cryptosporidium parvum TUM1 strain. Int. J. Parasitol. 40:146975.

Certad, G, Ngouanesavanh, T, Guyot, K, Gantois, N, Chassat, T, et al, 2007: Cryptosporidium parvum, a potential cause of colic adenocarcinoma. Infect. Agent Cancer 2: 22.

Cooper, HS, Murthy, S, Kido, K, Yoshitake, H, Flanigan A, 2000: Dysplasia and cancer in the dextran sulfate sodium mouse colitis model. Relevance to colitis-associated neoplasia in the human: a study of histopathology, $\beta$-catenin and p53 expression and the role of inflammation. Carcinogenesis. 21,757-768.

Current, WL, Reese, NC, Ernst, JV, Bailey, WS, Heyman, MB, Weinstein, WM, 1983: Human cryptosporidiosis in and immunodeficient persons: Studies of an outbreak and experimental transmission. N. Engl. J. Med. 308: 1252-7.

Curtis, TY, Powers, SJ, Balagiannis, D, Elmore, JS, Mottram, DS, et al., 2010: Free amino acids and sugars in rye grain: implication for acrylamide formation. J. Agric. Food Chem. 58: 1959-69.

De Martel, C, Franceschi, S, 2009: Infections and cancer: established associations and new hypotheses. Crit. Rev. Oncol. Hematol. 70:18394.

Dieleman, LA, Palmen, MJHJ, Akol, H, Bloemena, E, Pena, SA, et al, 1998: Chronic experimental colitis induced by dextran sulphate sodium (DSS) is characterized by Th1 and Th2 cytokines. Clin. Exp. Immunol. 114:385-91.

Drury, RAB, Wallington, EA, 1980: Carleton's Histological Technique. 5th ed. Oxford University Press, Oxford, New York, Toronto.

Everly, DNJ, Jr-Kusano, S, Raab-Traub, N, 2004: Accumulation of cytoplasmic beta-catenin and nuclear glycogen synthase kinase 3beta in Epstein Barr virus-infected cells. J. Virology. 78:11648-55.

Fleta, J, Sanchez-Acedo, C, Clavel, A, Quilez, J, 1995: Detection of Cryptosporidium oocysts in extraintestinal tissues of sheep and pigs. Vet. Parasitol. 59, 201-205.

Franchimont, D, 2004: Overview of the actions of glucocorticoids on the immune response: a good model to characterize new pathways of immunosuppression for new treatment strategies. Ann. N. Y. Acad. Sci. 1024:124-37. 
Gaafar, MR, 2007: Effect of solar disinfection on viability of intestinal protozoa in drinking water. J. Egypt. Soc. Parasitol. 37, 1:65-86.

Garcia, LS, and Bruckner, DA, 1997: Macroscopic and microscopic examination of fecal specimens. In: Diagnostic Medical Parasitology. $3^{\text {rd }}$ ed. Washington D. C., A. M. S. Press.

Garcia, LS, 2007: Clinically important human parasites: Intestinal protozoa: Cryptosporidium spp. In: Diagnostic Medical Parasitology. $5^{\text {th }}$ ed. A. S. M. press, Washington D. C.

Godbole GB, Modi, DN, Puri, CP, 2007: Regulation of homeobox A10 expression in the primate endometrium by progesterone and embryonic stimuli. Reproduction 134:513-23.

Heussler, VT, Kuenzi, P, Rottenberg, S, 2001: Inhibition of apoptosis by intracellular protozoan parasites. Int. J. Parasitol. 31:1166-76.

Hunter, PR, Nichols, G, 2002: Epidemiology and clinical features of Cryptosporidium infection in immunocompromised patients. Clin. Microbiol. Rev. 15:145-54.

Kaur, J, Sawhney, M, Dattagupta, S, Shukla, $\mathrm{K}$, Srivastava, A, et al, 2013: Clinical significance of altered expression of B-catenin and Ecadherin in oral dysplasia and cancer: Potential link with ALCAM expression. PLoS One 28, 8 (6).

Khalifa, AM, El Temsahy, MM, Abou EI Naga, IF, 2001: Effect of ozone on the viability of some protozoa in drinking water. J. Egypt. Soc. Parasitol. 31, 2:603-16.

Kudo, Y, Kitajima, S, Ogawa, I, Hiraoka, M, Sargolzaei, S, et al, 2004: Invasion and metastasis of oral cancer cells require methylation of Ecadherin and/or degradation of membranous beta-catenin. Clin. Cancer Res. 10:5455-63.

Liang YS, Bruce, JI, Boyd, DA, 1987: Proceeding of the First Sino-American Symposium.1:34-48.

Lowe, SW, Lin, AW, 2000: Apoptosis in cancer. Carcinogenesis 21, 485-495.

Lumb, R, Swift, J, James, C, Papanaoum, K, Mukh-erjee, T, 1993: Identification of the microsporidian parasite, Enterocytozoon bieneusi in fecal samples and intestinal biopsies from an AIDS patient. Int. J. Parasitol. 23:793-801.

Molloy, SF, Smith, HV, Kirwan, P, Nichols, RAB, Asaolu, SO, et al., 2010: Identification of a high diversity of Cryptosporidium species genotypes and subtypes in a pediatric population in Nigeria. Am. J. Trop. Med. Hyg. 82, 4:608-13.

29.
Parkin, DM, 2006: The global health burden of infection-associated cancers in the year 2002 . Int. J. Cancer 118:3030-44.

Patel, P, Hanson, DL, Sullivan, PS, Novak, R M, Moorman, AC, et al, 2008: Adult and adolescent spectrum of disease project and HIV outpatient study investigators: Incidence of types of cancer among HIV-infected persons compared with the general population in the United States, 1992-2003. Ann. Intern. Med. 148:728-36.

Rehg, JE, Hancock, ML, Woodmansee, DB, 1988: Characterization of a dexamethasonetreated rat model of cryptosporidial infection. J. Infect. Dis. 158:1406-7.

Sayon B, Gal, H, Avri, BZ, 2016: Wnt signaling in cancer stem cells and colon cancer metastasis. Version1. F1000Res. 5, F1000 Faculty Rev-699. doi: 10.12688/f1000research.7579.1

Stojadinovic, O, Lee, B, Vouthounis, C, Vukelic, S, Pastar, I, et al, 2007: Novel genomic effects of glucocorticoids in epidermal keratinocytes: inhibition of apoptosis, interferon-gamma pathway, and wound healing along with promotion of terminal differentiation. J. Biol. Chem. 282:4021-34.

Taha, NM, Yousof, H-ASA., El-Sayed, SH, Younis, AI, Negm, MSI, 2017: Atorvastatin repurposing for the treatment of cryptosporidiosis in experimentally immunosuppressed mice. Exp. Parasitol. 181:57-69.

Takahashi, M, Mutoh, M, Kawamori, T, Sugimura, T, Wakabayashi, K, 2000: Altered expression of beta-catenin, inducible nitric oxide synthase and cyclooxygenase- 2 in azoxymethane-induced rat colon carcinogenesis. Carcinogenesis. 21:1319-27.

Wanyiri, J, Ward, H, 2006: Molecular basis of Cryptosporidium-host cell interactions: Recent advances and future prospects. Future Microbiol. 1:201-8.

Xiao, L, 2010: Molecular epidemiology of cryptosporidiosis: An update. Exp. Parasitol. 124:809.

Xin-Tian, Z, Ai-Yu, G, Yang, W, Xiqiang, C, Sheng-Yau, SL, et al, 2016: Cryptosporidium parvum infection attenuates the ex vivo propagation of murine intestinal enteroids. Physiological Reports.4:24-30.

Yang, J, Weinberg, RA, 2008: Epithelial-mesenchymal transition: at the crossroads of development and tumor metastasis. Dev. Cell. 14:818- 


\section{Explanation of figures}

Fig. 1: sections of ileum (H \& E, x200) in: (A) G4b showed moderate villous atrophy with broadening, (B) G5c showed severe villous atrophy with heavy infiltration of inflammatory cells and sections of colon in G5c showed (C) moderate colitis with moderate exudation of mononuclear inflammatory cells (arrow) (H \& E, x400) (D) Mononuclear inflammatory cells with pleomorphic hyperchromatic nuclei (black arrows) and red arrows showed Cryptosporidium oocysts on crypts surface (H \& E, x1000).

Fig. 2: IHC for $\beta$-catenin in sections from: (A) colon in non-infected control group showed moderate predominantly membranous staining, (B) ileum in G2a showed diffuse mild to moderate membranous and mild cytoplasmic $\beta$-catenin staining, (C) ileum in G3c showing diffuse moderate membranous and mild cytoplasmic $\beta$-catenin staining and (D) colon in G5c showed moderate cytoplasmic $\beta$-catenin expression (Hx \& E, x400) (E) colon in G5c showed plenty of Cryptosporidium oocysts expressing $\beta$-catenin staining (black arrows) (HPX 1000) (F) IHC for p53 in section of colon in G5c showed focal mild cytosolic p53 labeling in lamina propria (arrows) (HPX 400)
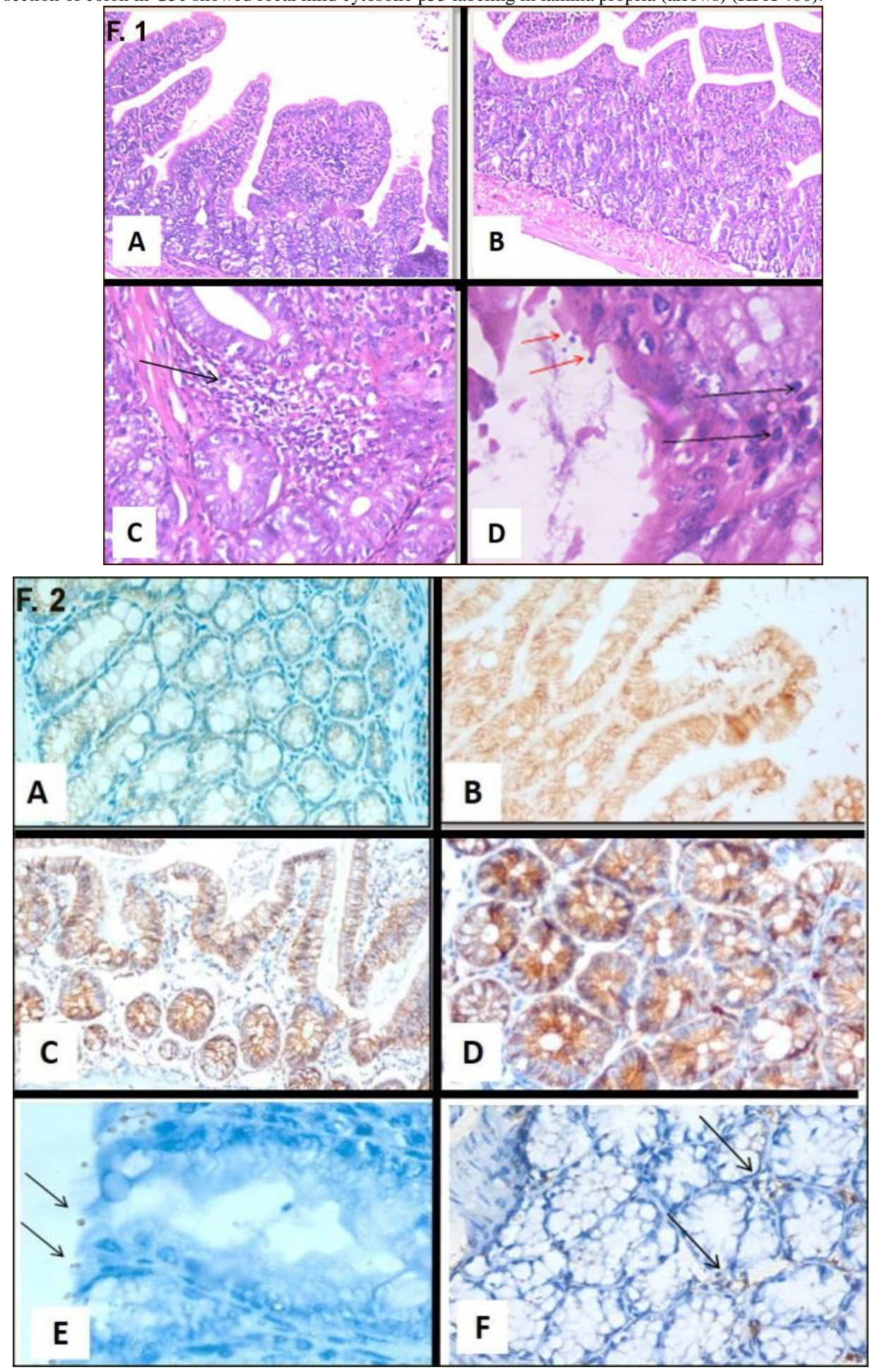